Scripta Neophilologica Posnaniensia. Tom XV, strony: 7-12

Wydział Neofilologii, Uniwersytet im. Adama Mickiewicza w Poznaniu, 2015

DOI 10.7169/snp.2015.15.01

\title{
THE ROLE OF ARMENIAN LANGUAGE IN THE PRESERVATION OF ARMENIAN IDENTITY
}

\author{
TATEVIK ARAKELYAN
}

There are over 6,800 languages spoken in the world. Armenian is one of the oldest of these living languages. It is the official language of the Republic of Armenia and other regions in the Caucasus. It is also the mother tongue of the Armenians living in the Diaspora.

The Armenian nation is in the active phase of the struggle for survival on a fraction of its own homeland, preserved at the cost of unimaginable sacrifices. In other words, the Armenian nation is a struggling organism whose main, vitally important function is the struggle for survival.

The frontlines of this struggle for survival stretch out not only along Armenia's borders with Azerbaijan and Turkey, but evidently also throughout the country itself, embracing the spheres of demography, economy, social life, science and education. Emigration, regardless of its reasons, removes Armenians, partially or fully, from the central battlefield for survival, that is - Armenia.

The population of Armenia is about $3 \mathrm{mn}$, and more than $9 \mathrm{mn}$ Armenians are spread abroad having formed highly organized diaspora communities with a long history of diaspora tradition.

Armenian education has always been an important concern of these communities, and a large network of Armenian elementary and secondary schools have been established in all parts of the world. The Armenian language continues to be a primary and natural medium of communication for the local Armenian population, and it is no coincidence that a large number of Armenian newspapers and periodicals have been published and the Armenian literary tradition has been 
preserved and developed in these countries. The existence of numerous national and cultural organizations, educational institutions, and the Armenian-language press have created a distinctive Armenian atmosphere in the primarily Armenian-populated districts. The cultural and educational progress of the Middle Eastern communities have been greatly assisted by the consistent financial support of the Armenian communities in the Western countries, primarily the United States. This assistance made it possible to establish schools, youth centers, and clinics, and to disperse scholarships funds. Armenian schools and other community structures have always functioned effectively. School is for the children to be given a good foundation in Armenian language, history, religion, culture and tradition which will enhance in them the sense of being Armenians.

Yet, today Armenia itself faces the full weight of the challenge of preserving and developing the Armenian language (i.e. culture). This is due to the decrease in the number of users of the Armenian language (including the potential users children who received and receive non-Armenian education abroad) attributable to the emigration of Armenians.

During the last decades the inevitable acculturation and assimilation processes in Diaspora have accelerated. In particular, as a result of emigration, every year the ranks of the Armenian communities are thinning out in the Middle East, where until recently the percentage of mixed marriages are getting lower and lower.

There is no Armenian culture without the Armenian language. Along with the statehood and the territory under its control, the language is the foundation and paramount means of preserving the Armenian ethnicity.

Thus the Government of Armenia has undertaken certain measures to preserve the Armenian language and the Armenian ethnicity.

Ministry of Diaspora of RA - was set up to implement and continuously improve the state policy on development of the Armenia-Diaspora partnership and coordinate the activities of the state bodies. The main objective of the Armenia-Diaspora partnership is to protect the fundamental rights, liberties and legal interests of Armenians in the historical Homeland or abroad, within the framework of international law and to defend the qualities of Armenian national identity, that is, preservation of Armenian identity.

The Ministry has developed and is carrying out potential pan-Armenian projects aimed at developing the Armenia-Diaspora partnership. Alongside with political, economic, cultural, legal and spiritual projects the Ministry carries out programs and projects aimed at Armenian language preservation.

\section{1. "Diaspora" Summer School}

The goal of the program is to turn Armenia into a center for studies on Armenian language and culture and teacher training. The school is located at 
Yerevan State University and includes $2-3$ week courses. The school has 5 departments, including

- School for Young Leaders

- School for Diaspora Armenian Journalists

- Advanced Course on Armenian Language

- Training Course for Diaspora Armenian Teacher

- Training Course for Cultural Figures, Teachers of Song and Dance and Group Directors

2. Participation in the process of training experts on the Diaspora of the YSU Department of Diaspora Studies

- To prepare and train cadres in the sphere of Diaspora studies, the Ministry of Diaspora established the Master's program for Diaspora Studies in the Department of Diaspora Studies at Yerevan State University.

- The Ministry develops the topics for research that interest students, organizes lectures, manages the students' internships and helps 12 students pay their tuitions.

3. Preparation or ordering of informative materials (films, video clips, articles, TV and radio programs, advertisements); supervision of the publication and website service for the "Hayern Aysor" (Armenia today) online newspaper and the provision of corresponding materials; study and summary of articles printed in Diaspora Armenian media

4. Development of programs for support to the solution of key educational and cultural issues in the Armenian communities of the CIS and the coordination of implementation

- On-site teacher training at Armenian schools in the CIS countries

- Procurement of curricula, textbooks and methodological materials for the instruction of Armenian subjects in a Russian-speaking and Ukrainianspeaking environment and their provision to the communities

- Support to the improvement of the network of one-day schools in Armenian communities

- Organizing of the "Hye Aspet" (Armenian Knight) TV game show with the participation of schoolchildren from Armenian schools in the region

- Organizing of student Olympiads and essay contests related to studies on patriotism in the communities

- Organizing of instructional, productive and pre-graduation internships for Armenian students of universities of CIS countries in Armenia

- Support to the establishment of Armenology centers at educational institutions in the region and the introduction of an Armenology course in the curricula of scientific and educational institutions 
- Organizing of concerts and performances of cultural and creative groups and individual performers from Armenia in the communities

- Organizing of meetings with the participation of representatives of Armenian youth organizations in the region

- Organizing of an annual festival called "Yes Im Anush Hayastani" with the participation of theatre companies and art groups from the region

- Creation of correspondent points for the "Hayern Aysor" multilingual online newspaper of the RA Ministry of Diaspora hinged on Armenian media in the region

- Business trips of correspondents for program implementation to Armenian communities

\section{Creation of unified textbooks in Western Armenian}

To confront the linguistic-cultural assimilation in the Diaspora, especially among the Western-Armenian speakers and to preserve the national identity, the ministry places high importance on the study of educational issues in the Diaspora, the support for their solutions, particularly the creation of unified programs and textbooks.

The scientific conference on "Principles of Unified Textbooks in Western Armenian" and the workshop on "Current State of Western Armenian in the Diaspora" led to the creation of a coordinating council the Western Armenian language experts of which will work together for the creation of unified textbooks.

As a result, elementary, secondary and high schools will be provided with unified textbooks in Western Armenian and curricula, while elementary schools will have workbooks.

Ministry of Education and Science of RA - The government of the Republic of Armenia (RA), on behalf of the Ministry of Education and Science, gives special treatment to representatives of Armenian Diaspora when they are seeking to continue their education in Armenia. The Ministry of Education and Science of RA looks to make this education more available for the members of the Diaspora, promote interest in the Armenian cultural heritage for Diaspora youth, and support the development of Armenian studies.

By providing our Diaspora with a focused, purposeful, appropriate and qualified education, we hope to create qualified specialists, as well as create a strong bond with Armenia and encourage our Diaspora to return to their homeland.

Members of Diaspora may apply for admission to RA Higher Education Institutions (HEI) either on a general basis in accordance with the regulations assigned for the RA citizens, or in compliance with the special order issued for foreigners. 
Every year the Government of RA provides 70 scholarships for the Armenian Diaspora students pursuing bachelor's programmes in Armenian studies, pedagogy and art.

\section{Linguistics in Armenia}

Armenian linguistics is based on the age-long history of Armenian grammatical mind on the one hand, which has always reflected the high level of the worldwide science of its time. On the other hand it is based on the modern achievements of native and foreign linguistics. It was rapidly developed especially in the 20-th century when the Armenian statehood was established (1918) and the Armenian language acquired the status of the state language of the RA, with its forthcoming functional comprehensiveness, broad abilities of development, improvement and investigation. Armenian has become a subject of comprehensive research for different linguistic scientific categories, which examine fundamental questions concerning its origin, historical development, inner structure and social functions. Researches are carried out in all the spheres of Armenology - contrastive and comparative examination of Armenian and other languages, the typological characterization of Armenian, historical-comparative grammar, dialectology, the theory and history of language, the description of its structure in various phases of development - phonetics and phonology, lexicology, phraseology, stylistics, terminology and lexicography.

In the middle of the 20-th century new spheres for Armenian linguistics were developed - psycho-linguistics, socio-linguistics, structural linguistics, mathematical linguistics and the formative description of the language, the typological contrastive study of Armenian, historical dialectology and linguistic geography. The questions concerning the elaboration and regulation of literary language, term-building, culture of speech, spelling and orthoepy as well as other questions of practical type are in the centre of Armenologists' attention.

If in the beginnings of the 19-th and 20-th centuries Armenology was mainly developed in European scientific centers, where the scientists' attention was called to the comparative study of the language, thus in the 50's of the 20-th century Armenia became the leading centre for Armenology and the comprehensive investigation of all the manifestations and variants of Armenian.

At present, Armenian linguistics is a system of linguistic scientific categories, the main directions of which being the comprehensive study of Armenian, the contrastive-typological research of languages, general and comparative linguistics. Great importance is given to the Armenian language as a guarantee for preservation of national self-sufficiency and further independent development of the RA for future comprehensive development and an important strategic means of unobstructed usage. Thus, the main problem of Armenology is considered to be the research, regulation, elaboration, perfection of Armenian, the realization 
of which is in need of both the state's care and scientific and methodological justification.

In spite of the fact that the scientific potential had a decrease during the beginning of the 90's connected with the political and economic hardships of the transitional period, Armenian linguistics did not cease to long for the preservation of the traditional fields of Armenological researches and the utilization of new spheres. And if there was some decrease in theoretical works due to practical directions in the above mentioned period (the compilation of different dictionaries, directories, textbooks, self-taught manuals, phrasebooks, etc.) then in the recent years the interest in linguistic fundamental questions which relate to the various parts and structural levels of the language as well as to its territorial, social and historic variants has risen. Researches presented to the coverage of complex and contentious issues are carried out which are associated with the Armenian comparative grammar (the state of protoArmenian, sublevel phenomena, the reflection of Indo-European alternations in Old Armenian, the facts of comparative mythology, etc.), the historical development (the development and formation of Western and Eastern Armenian literary variants, especially the language of poetry, linguistic neologisms, the enrichment of the word stock by means of own word-building ways as well as borrowings and calques), linguistic facts in Armenia and Diaspora conditioned by ethnographical procedures (bilingualism and multilingualism, literary, informal and dialectal variants, their corelation and social conditionality) and other aspects.

Connected with inter-linguistic and cross-cultural relations and in the consequence of the immigration of masses who don't master Armenian, there also appear unwanted linguistic influences, improper loans, negative linguistic penetrations, fall in the culture of speech, etc. The problems concerning the teaching of the mother tongue, the purity of the literary language, the increase in the culture of speech in public as well as in press and mass media, the correct use of the language gain special importance.

The Institute of Language after H. Acharyan of the National Academy of Sciences of the Republic of Armenia (IL NAS RA) was founded in 1943. The Institute was and is firstly concerned with fundamental questions of Armenological studies, especially with the questions related to the structure and function of the Armenian language, the research of Armenian dialects, the history of Armenian and comparative grammar. 